\title{
Prevalence and correlates of intimate partner violence among family planning clients in Conakry, Guinea
}

\author{
Alexandre Delamou ${ }^{1,2^{*}}$, Ghazaleh Samandari ${ }^{3}$, Bienvenu Salim Camara², Pernamou Traore ${ }^{4}$, \\ Fatoumata Guilinty Diallo ${ }^{5}$, Sita Millimono ${ }^{6}$, Defa Wane ${ }^{3}$, Maimouna Toliver ${ }^{3}$, Kira Laffe ${ }^{6}$ and Fabio Verani ${ }^{3}$
}

\begin{abstract}
Background: Intimate partner violence (IPV) is a global public health problem that affects women's physical, mental, sexual and reproductive health. Very little data on IPV experience and FP use is available in resource-poor settings, such as in West Africa. The aim of this study was to describe the prevalence, patterns and correlates of IPV among clients of an adult Family Planning clinic in Conakry, Guinea.
\end{abstract}

Methods: The study data was collected for four months (March to June 2014) from women's family planning charts and from an IPV screening form at the Adult Family Planning and Reproductive Health Clinic of "Association Guinéenne pour le Bien-Etre Familial", a non-profit organization in Conakry, Guinea. 232 women out of 245 women who attended the clinic for services during the study period were screened for IPV and were included in this study.

Results: Of the 232 women screened, 213 (92\%) experienced IPV in one form or another at some point in their lifetime. 169 women reported psychological violence (79.3\%), 145 reported sexual violence (68.1\%) and 103 reported physical violence (48.4\%). Nearly a quarter of women reported joint occurrence of the three forms of violence(24 \%). Half of the IPV positive women were current users of family planning (51.2\%) and of these, $77.9 \%$ preferred injectable contraceptives. The odds of experiencing IPV was higher in women with secondary or vocational level of education than those with higher level of education (AOR: 8.4; $95 \%$ Cl 1.2-58.5). Women residing in other communes of Conakry (AOR: 5.6; $95 \%$ Cl 1.4-22.9) and those preferring injectable FP methods (AOR: 4.5; $95 \%$ Cl 1.2-16.8) were more likely to experience lifetime IPV.

Conclusions: IPV is prevalent among family planning clients in Conakry, Guinea where nine out of ten women screened in the AGBEF adult clinic reported having experienced one or another type of IPV. A holistic approach that includes promotion of women's rights and gender equality, existence of laws and policies is needed to prevent and respond to IPV, effective implementation of policies and laws, and access to quality IPV services in Guinea and countries with higher rates of IPV.

Keywords: Intimate partner violence, Family planning, Prevalence, Correlates, Factors, Patterns, Guinea

\section{Background}

Intimate partner violence (IPV) is a serious violation of one's human rights and a public health problem that affects women's physical, mental, sexual and reproductive

\footnotetext{
*Correspondence: adelamou@gmail.com

${ }^{1}$ Centre National de formation et de recherche en santé rurale de

Maferinyah, Forécariah, Guinea

Full list of author information is available at the end of the article
}

health worldwide [1, 2]. According to a recent World Health Organization (WHO)'s report, more than one in three women (35.6\%) globally and $36.6 \%$ in Africa have experienced physical and/or sexual violence [3, 4]. The lifetime physical and/or sexual IPV prevalence has been reported to vary from 15 to $71 \%$ in ten countries worldwide [3]. Intimate partners perpetrate more than a third of female homicides, worldwide [5]. Survivors of IPV are less likely to use reproductive health services [6] and 
more likely to experience adverse reproductive health outcomes such as low birth weight infants, pre-term delivery and neonatal death [1].

The prevalence of IPV among women has already been documented in different settings using population based studies [7-10], women living with HIV [11, 12] and those whom are pregnant $[13,14]$. Furthermore, a few studies including data from West African countries suggest that women experience a high rate of physical or sexual violence, up to $76 \%$ of women $[15,16]$. Additionally, previous studies have examined the use of contraceptives among women who experienced IPV $[17,18]$. However, very little empirical data exist on the experience of IPV in women in West Africa, generally, and Guinea, specifically. Furthermore, these data are typically gathered in the context of violent political conflict and do not capture the contraceptive pattern of survivors. Guinea has a low contraceptive prevalence rate $(7 \%)$ that has not improved since 1999 , and the maternal mortality ratio is estimated to be 724 per 100,000 Live Births $[19,20]$, indicating a need to improve family planning services overall, and in particular for women struggling with IPV. By examining IPV experience among a sample of family planning clients, we hope to better understand characteristics of women experiencing violence in this population and their preferred patterns of contraception.

From January to June 2014, a pilot project for the integration of IPV screening and counseling into FP services was implemented in the adult family planning clinic of the Association Guineenne pour le Bien-etre Familial (AGBEF), a member association of the International Planned Parenthood Association (IPPF) in Conakry, Guinea [21].

In this study, we report on: (1) the sociodemographic characteristics of IPV among family planning clients, (2) the types of IPV experienced by family planning clients and, (3) factors associated with types of IPV among clients.

\section{Methods}

\section{Study design}

The data for this study were derived from a pilot project conducted by the RESPOND Project, led by EngenderHealth and in partnership with AGBEF. This project piloted the integration of IPV screening and counseling into existing family planning services [21].

The study data was collected for four months (March to June 2014) from women's family planning charts and from an IPV screening form at the Adult Family Planning and Reproductive Health Clinic of AGBEF, a non-profit organization in Conakry, Guinea.

\section{Study setting}

\section{Study site}

AGBEF is a Member Association of the International Planned Parenthood Federation (IPPF). The organization operates 9 clinics in Guinea, including one youth clinic and one adult clinic in Conakry. The pilot IPV-FP integration approach was implemented at the adult family planning clinic in Conakry. The clinic staff included a nurse and midwife in charge of FP provision, antenatal care and sexually transmitted infections (STI) screening and care; a counselor who provided counseling and family planning methods to clients and support/administrative staff.

\section{The Guinea IPV pilot project}

The project aimed at supporting improved reproductive health $(\mathrm{RH})$ by integrating IPV screening and counseling into FP services. The integration approach was based on creating a safe and enabling environment in which clients felt comfortable disclosing their experience(s) of IPV. It built on the GATHER (Greet, Ask, Tell, Help, Explain and plan the Return) Model for Family Planning Counseling [22] which the AGBEF clinic was using and staff was familiar with, providing additional consideration for IPV screening and services referral. This approach combined the basic tenets of respectful and informed client interaction with guidance on where and how to integrate IPV screening and counseling.

The main interventions of the project included conducting formative research; developing an IPV-FP integration curriculum; field testing the curriculum; providing the clinic with follow-up technical assistance and, evaluating the results of the pilot project. Full documentation of the RESPOND IPV pilot project is described elsewhere [21].

\section{Study population}

All women of reproductive age attending the clinic and seeking family planning services (new and current users) were eligible for recruitment. Women providing informed consent were screened for IPV. In total, 245 women attended the clinic for services during that study period. Of these, 232 consented to be screened for IPV and were included in data collection.

\section{Data variables, sources of data and data collection}

The IPV screening questionnaire was composed of nine questions informed by different screening question instruments [23, 24]. IPV was defined in this study as any experience of abusive behaviors and actions perpetrated by any intimate partner during their lifetime, and included psychological, physical and sexual abuse. Sociodemographic characteristics included age (in years), marital status (married/cohabitated or not married -single, divorced, or widow), occupation (housewife, workwoman, seller, employee or student), occupation of woman's partner (unemployed, workwoman, seller, employee or 
student), woman and her partner's level of education (none, primary, secondary/vocational or university), residence (Dixinn commune or other communes), number of live children. Other variables included contraceptive method use (injectable, pills, Intra-uterine device, IUD or implants), reasons for choosing the method (discretion, fertility return, not constraining or easy to use) and duration of FP use. For data collection, first an IPV documentation form was used after the counseling session by the midwife/nurse to screen the client for IPV and to classify the behavior as psychological, physical or sexual, a combination of two, or all three forms of IPV. Second, the women's medical records were used to extract sociodemographic information and family planning use.

\section{Data analysis}

Data collected from family planning clients was double entered, by two independent encoders, into a file using EpiData Entry software (version 3.1, EpiData Association, Odense, Denmark). The two data files were compared and discordances resolved by cross-checking with the source documents. Data was analysed using STATA 13 software (STATA Corporation, College Station, TX, USA). Frequencies (\%) were calculated to describe women's characteristics, contraceptive use and IPV types. Pearson's Chi square or Student $t$ test were used, respectively, to compare proportions or means of variables with a level of significance set at $\mathrm{P}=0.05$ and a $95 \%$ confidence intervals. Sociodemographic factors and contraceptive use correlated with lifetime prevalence of any type of IPV were assessed using logistic regression. All study variables were considered "a priori" for inclusion in the logistic regression model and contraceptive use was dichotomized (injectable versus non injectable). The adequacy of the final model was tested by the Hosmer and Lemeshow test for goodness of fit. Unadjusted and adjusted odds ratios and their $95 \% \mathrm{CI}$ were derived with a significance level set at $5 \%$.

\section{Ethics approval}

The study protocol was approved by the National Ethics Committee for Health Research of Guinea. Written informed consent was obtained from all participants prior to IPV screening. All interviews were conducted in complete privacy and data collection tools were strictly anonymous. A safety plan was discussed and elaborated with women found IPV positive and referral to a partner local organization offered care and follow up for victims of gender-based violence was discussed with women [21].

\section{Results}

Overall, 245 women attending the AGBEF adult FP/RH clinic in Conakry were provided counseling and IPV screening during the study period. Of them, 232 women provided an informed consent and accepted screening and 213 out of them were screened positive for IPV, meaning they have experienced one or more form of IPV.

\section{Sociodemographic characteristics}

The sociodemographic characteristics of the women are presented in Table 1. The mean age of participants was 28.5 years $( \pm 7.9 \mathrm{SD}), 60 \%$ were unmarried, and the majority of women had none or primary level of education (55.4\%). The mean number of pregnancies were 2.8 $( \pm 2.0 \mathrm{SD})$ and the mean number of live children was 2.4 $( \pm 1.8 \mathrm{SD})$. Women reported that their intimate partners were mainly business owners (33.3\%) or employed by others $(28.2 \%)$, and most had secondary to higher level of education (54.5\%).

\section{Lifetime prevalence and types of violence}

In this study, 213 (92\%, $95 \%$ CI 88.5-95.5\%) of the respondents experienced IPV in one form or another at some point in their lifetime. 169 women reported psychological violence (79.3\%), 145 reported sexual violence (68.1\%) and 103 reported physical violence (48.4\%), (Table 2).

Figure 1 shows the patterns of the joint occurrences of different forms of IPV among family planning clients screened. Psychological violence (34 women, $15 \%$ ) and sexual violence $(11 \%)$ were more likely to occur in isolated form compared to physical violence (3\%). 147 women (63\%) experienced more than one type of IPV. The joint occurrence of the three forms of violence was the most common (57 women, $24 \%$ ) followed by the joint occurrence of psychological and sexual violence (51 women, $22 \%$ ).

\section{Family planning practices}

Half of the 213 women who were IPV positive were current users of family planning $(51.2 \%)$ with a remarkable preference for injectable contraceptives $(77.9 \%)$. The majority of women preferred injectable methods irrespective of their IPV status (positive or negative) and of the type of violence experienced (psychological, physical and sexual). The main reasons for preferring injectable were discretion ( 75 women, $71 \%$ ), lack of constraints (14 women, $13 \%$ ) and fertility return (11 women, $10.5 \%$ ).

\section{Correlates of lifetime IPV}

Table 3 shows the results of the unadjusted and adjusted logistic regression modelling performed to identify the correlates of lifetime experience of IPV.

\section{Unadjusted analysis}

In bivariate analyses, lifetime IPV was significantly associated with woman's level of education, residence of the 
Table 1 Socio-demographics characteristics of family planning clients screened for Intimate partner violence (IPV) at the AGBEF Clinic from March to June 2014 in Conakry, Guinea

\begin{tabular}{|c|c|c|}
\hline Variables & $\begin{array}{l}\text { Screened for } \\
\text { IPV number (\%) }\end{array}$ & $\begin{array}{l}\text { IPV positive } \\
\text { number } \\
(\%)\end{array}$ \\
\hline Total & 232 & 213 \\
\hline \multicolumn{3}{|l|}{ Age, years } \\
\hline $15-19$ & $27(11.6)$ & $24(11.3)$ \\
\hline $20-24$ & $61(26.3)$ & $58(27.2)$ \\
\hline $25-34$ & $81(34.9)$ & $74(34.7)$ \\
\hline $35-49$ & $63(27.2)$ & $57(26.8)$ \\
\hline Mean (SD) & $28.7(8.0)$ & $28.5(7.9)$ \\
\hline \multicolumn{3}{|l|}{ Marital status } \\
\hline Married & $94(40.5)$ & $86(40.4)$ \\
\hline Not married & $138(59.5)$ & $127(59.6)$ \\
\hline \multicolumn{3}{|l|}{ Occupation } \\
\hline Housewife & $21(9.1)$ & $20(9.4)$ \\
\hline Workwoman & $40(17.2)$ & $38(17.8)$ \\
\hline Seller & $85(36.6)$ & $80(37.6)$ \\
\hline Employee & $36(15.5)$ & $32(15.0)$ \\
\hline Student & $50(21.6)$ & $43(20.2)$ \\
\hline \multicolumn{3}{|l|}{ Level of education } \\
\hline None & $73(31.5)$ & $67(31.5)$ \\
\hline Primary & $55(23.7)$ & $51(23.9)$ \\
\hline $\begin{array}{l}\text { Secondary and vocational } \\
\text { school }\end{array}$ & $74(31.9)$ & $71(33.3)$ \\
\hline University & $30(12.9)$ & $24(11.3)$ \\
\hline \multicolumn{3}{|l|}{ Residence } \\
\hline Dixinn & $105(45.3)$ & $102(47.9)$ \\
\hline Other communes & $127(54.7)$ & $111(52.1)$ \\
\hline \multicolumn{3}{|l|}{ Partner occupation } \\
\hline Unemployed & $37(15.9)$ & $32(15.0)$ \\
\hline Workman & $38(16.4)$ & $35(16.4)$ \\
\hline Seller & $77(33.2)$ & $71(33.3)$ \\
\hline Employee & $64(27.6)$ & $60(28.2)$ \\
\hline Student & $16(06.9)$ & $15(07.1)$ \\
\hline \multicolumn{3}{|l|}{ Partner's level of education } \\
\hline None & $68(29.3)$ & $64(30.0)$ \\
\hline Primary & $38(16.4)$ & $33(15.5)$ \\
\hline $\begin{array}{l}\text { Secondary and vocational } \\
\text { school }\end{array}$ & $77(33.2)$ & $70(32.9)$ \\
\hline University & $49(21.1)$ & $46(21.6)$ \\
\hline \multicolumn{3}{|l|}{ Number of pregnancies } \\
\hline 0 & $28(12.0)$ & $23(10.8)$ \\
\hline 1 & $51(22.0)$ & $48(22.5)$ \\
\hline $2-4$ & $109(47.0)$ & $101(47.4)$ \\
\hline$\geq 5$ & $44(19.0)$ & $41(19.3)$ \\
\hline Mean (SD) & $2.7(2.1)$ & $2.8(2.0)$ \\
\hline
\end{tabular}

Table 1 continued

\begin{tabular}{|c|c|c|}
\hline Variables & $\begin{array}{l}\text { Screened for } \\
\text { IPV number (\%) }\end{array}$ & $\begin{array}{l}\text { IPV positive } \\
\text { number } \\
(\%)\end{array}$ \\
\hline \multicolumn{3}{|l|}{ Number of live children } \\
\hline 0 & $30(12.9)$ & $25(11.7)$ \\
\hline 1 & $59(25.4)$ & $56(26.3)$ \\
\hline $2-4$ & $112(48.3)$ & $103(48.4)$ \\
\hline$\geq 5$ & $31(13.4)$ & $29(13.6)$ \\
\hline Mean (SD) & $2.4(1.8)$ & $2.4(1.8)$ \\
\hline \multicolumn{3}{|l|}{ Previous use of FP } \\
\hline No & $115(49.6)$ & $104(48.8)$ \\
\hline Yes & $117(50.4)$ & $109(51.2)$ \\
\hline $\begin{array}{l}\text { Mean duration of FP use (SD), } \\
\text { months }\end{array}$ & $6.6(10.3)$ & $6.9(10.6)$ \\
\hline \multicolumn{3}{|c|}{ Previous FP method used $(n=130)$} \\
\hline Injectable & $98(75.4)$ & $95(77.9)$ \\
\hline Pills & $06(04.6)$ & $06(04.9)$ \\
\hline IUD & $22(16.9)$ & $18(14.7)$ \\
\hline Implants & $04(03.1)$ & $03(02.5)$ \\
\hline \multicolumn{3}{|l|}{ FP method used at this visit } \\
\hline Injectable & $174(75.0)$ & $166(77.9)$ \\
\hline Pills & $10(04.3)$ & $09(04.2)$ \\
\hline IUD & $39(16.8)$ & $31(14.6)$ \\
\hline Implants & $09(03.9)$ & $07(03.3)$ \\
\hline \multicolumn{3}{|c|}{ Reasons for choosing this FP method } \\
\hline Discretion & $80(71.4)$ & $75(71.4)$ \\
\hline Fertility return & $11(09.8)$ & $11(10.5)$ \\
\hline Not constraining & $16(14.3)$ & $14(13.3)$ \\
\hline Easy & $05(04.5)$ & $05(04.8)$ \\
\hline
\end{tabular}

Table 2 Prevalence of Intimate partner violence (IPV) among women screened at the AGBEF Clinic from March to June 2014 in Conakry, Guinea

\begin{tabular}{lll}
\hline & $\begin{array}{l}\text { Among women } \\
\text { screened for IPV } \\
\mathbf{N}(\%)\end{array}$ & $\begin{array}{l}\text { Among IPV positive } \\
\text { women } \\
\mathbf{N}(\%)\end{array}$ \\
\hline $\begin{array}{l}\text { Total } \\
\text { Prevalence of IPV }\end{array}$ & 232 & 213 \\
IPV negative & $19(8.2)$ & $\mathrm{N} / \mathrm{A}$ \\
IPV positive & $213(91.8)$ & $\mathrm{N} / \mathrm{A}$ \\
$\begin{array}{l}\text { Type of IPV } \\
\begin{array}{l}\text { Psychological } \\
\text { violence }\end{array}\end{array}$ & $169(79.3)$ \\
$\begin{array}{l}\text { Physical violence } \\
\text { Sexual violence }\end{array}$ & & $103(48.4)$ \\
\hline
\end{tabular}




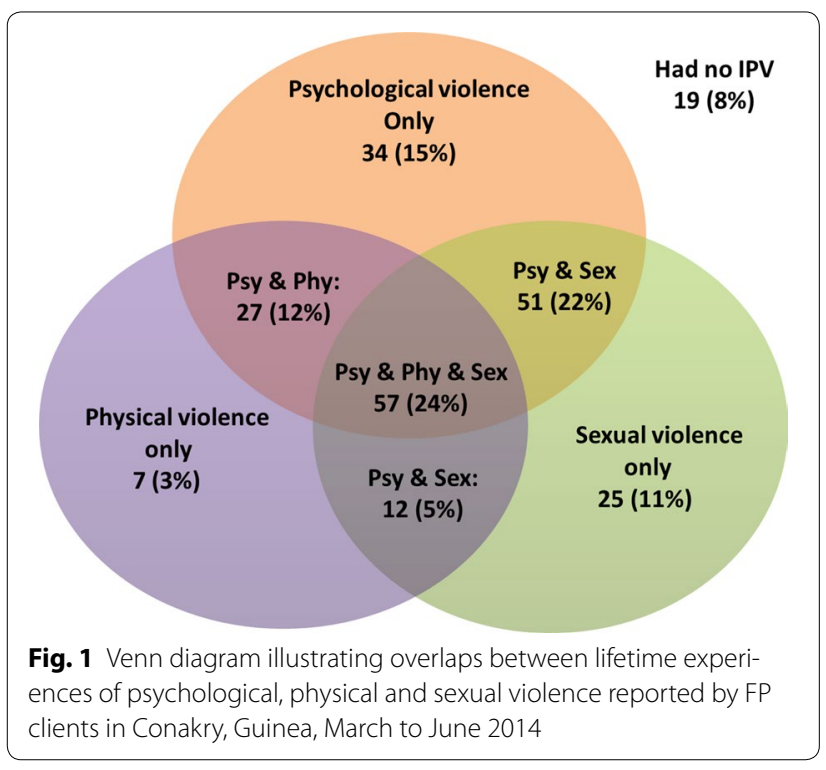

woman, and family planning method used. Women with a secondary to vocational level of education were more likely to experience lifetime IPV than women with higher level of education (Odds ratio (OR) 5.9; 95 \% Confidence Interval (95 \% CI) 1.4-25.5)

The odds of experiencing IPV was higher among women residing in other communes of Conakry (OR 4.9; 95 \% CI 1.4-17.3) compared with the Dixinn Commune where the AGBEF clinic was established. Finally, women who preferred injectable as FP method were more likely to experience IPV compared with those who preferred non injectable FP methods such as implants, IUD or pills (OR 4.9; 95 \% CI 1.9-12.8).

\section{Adjusted analysis}

After adjusting for possible confounding factors (Table 3), lifetime IPV remained significantly associated with woman's level of education, residence of the woman, and family planning method used.

The adjusted odds ratio (AOR) of experiencing IPV remained higher and even increased in women with secondary to vocational level of education as compared to those with higher level of education (AOR: 8.4; $95 \% \mathrm{CI}$ 1.2-58.5). Women residing in other communes of Conakry were more likely to experience lifetime IPV than women living in the Dixinn commune (AOR: 5.6; $95 \%$ CI 1.4-22.9). The odds of lifetime IPV remained higher in women preferring injectable FP methods as compared to women using non injectable methods (AOR: 4.5; $95 \%$ CI 1.2-16.8). Finally the results suggested an association between duration of FP use and lifetime occurrence of IPV (an $8 \%$ increase for each additional month of use) but the association was not statistically significant $(\mathrm{p}=0.093)$.

\section{Discussion}

This is one of the first studies reporting on the prevalence and correlates of IPV among family planning clients in West Africa, and specifically in Guinea. Overall, the study showed high prevalence of IPV among the study population (92\%). The prevalence observed in this study is greater than that reported in previous studies conducted on IPV across Africa, including Guinea [3, 8, 25, 26]. While psychological violence was the most common IPV type experienced by women (79\%), our results show that $63 \%$ of those screened experienced more than one type of IPV and almost one out of four women experienced the three types of IPV at some time in their life. Injectable contraceptive were the preferred family planning methods used by women, with discretion being the main reason for such choice.

After adjusting for possible confounding factors, lifetime IPV was significantly associated with woman having a secondary to vocational level of education, residence in communes other than Dixinn commune which hosts the FP clinic, and the use of injectable FP methods.

Our findings raise issues that merit further discussion.

First, the high prevalence observed in our study may be attributable to differences in measurement or it may be that women seeking FP services are particularly high risk, as seen in other studies $[3,8,17,18]$. For instance our sample included only women seeking family planning services in one clinic setting. The lifetime prevalence of IPV in women aged 15 to 49 years was estimated to be $62 \%$ in 2009 in Guinea [25]. The WHO population-based household surveys reported a lifetime prevalence of physical or sexual partner violence, or both, varying from 15 to $71 \%$ [3]. In a study by Alio et al. [17], women who had experienced IPV were significantly more likely to report having used contraception compared with women who had not experienced IPV (OR 1.30, 95 \% CI 1.22-1.38). In addition, contraceptive use has been reported to be 1.5 to 2 times higher in women exposed to IPV compared to women who were not in Jordan [18] and in Bangladesh [27].

Second, $78 \%$ of women in our study preferred injectable because they thought it was a discreet method. Women using injectable FP methods were more likely to experience lifetime IPV compared to those using non injectable methods in our context. This suggests that women who seek injectable may be in violent relationships and therefore want to hide their contraceptive use from their partner to avoid future violence. 
Table 3 Correlates of any type of IPV among FP clients at the AGBEF Clinic from March to June 2014, Conakry, Guinea $(\mathrm{N}=\mathbf{2 3 2})$

\begin{tabular}{|c|c|c|c|c|}
\hline & $\begin{array}{l}\text { IPV positive } \\
\mathrm{N}(\%)\end{array}$ & $\begin{array}{l}\text { Unadjusted } \\
\text { OR }(95 \% \mathrm{Cl})\end{array}$ & Adjusted $^{\mathrm{a}} \mathrm{OR}(95 \% \mathrm{Cl})$ & P-value \\
\hline Total & 232 & 232 & 232 & \\
\hline Age, years & $28.5(7.9)$ & $0.98(0.92-1.03)$ & $0.93(0.82-1.05)$ & 0.222 \\
\hline Marital status & & & & 0.954 \\
\hline Married & $86(91.5)$ & 1 & 1 & \\
\hline Not married & $127(92.0)$ & $1.07(0.41-2.78)$ & $0.96(0.23-3.92)$ & \\
\hline \multicolumn{5}{|l|}{ Woman's level of education } \\
\hline None & $67(91.8)$ & $2.79(0.82-9.49)$ & $0.75(0.06-9.02)$ & 0.820 \\
\hline Primary & $51(92.7)$ & $3.19(0.82-12.36)$ & $1.59(0.18-14.31)$ & 0.681 \\
\hline Secondary and vocational & $71(95.9)$ & $5.92(1.37-25.51)$ & $8.44(1.22-58.47)$ & 0.031 \\
\hline Higher & $24(80.0)$ & 1 & 1 & \\
\hline \multicolumn{5}{|l|}{ Woman's occupation } \\
\hline Housewife & $20(95.2)$ & $3.26(0.37-28.27)$ & $12.92(0.44-72.38)$ & 0.139 \\
\hline Workwoman & $38(95.0)$ & $3.09(0.60-15.80)$ & $7.18(0.51-100.21)$ & 0.143 \\
\hline Seller & $80(94.1)$ & $2.60(0.78-8.70)$ & $9.69(0.77-99.46)$ & 0.078 \\
\hline Employee & $32(88.9)$ & $1.30(0.35-4.83)$ & $2.56(0.36-18.33)$ & 0.349 \\
\hline Student & $43(86.0)$ & 1 & 1 & \\
\hline Residence & & & & 0.016 \\
\hline Dixinn & $111(87.4)$ & 1 & 1 & \\
\hline Other communes & $102(97.1)$ & $4.90(1.39-17.31)$ & $5.60(1.37-22.85)$ & \\
\hline \multicolumn{5}{|l|}{ Partner occupation } \\
\hline Unemployed & $32(86.5)$ & 1 & 1 & 0.291 \\
\hline Workman & $35(92.1)$ & $1.82(0.40-8.25)$ & $2.83(0.41-19.50)$ & 0.306 \\
\hline Seller & $71(92.2)$ & $1.85(0.52-6.51)$ & $2.33(0.46-11.85)$ & 0.269 \\
\hline Employee & $60(93.8)$ & $2.34(0.59-9.34)$ & $2.75(0.46-16.64)$ & 0.783 \\
\hline Student & $15(93.8)$ & $2.34(0.25-21.86)$ & $0.63(0.02-16.28)$ & \\
\hline \multicolumn{5}{|l|}{ Partner's level of education } \\
\hline None & $64(94.1)$ & $2.42(0.61-9.64)$ & $3.77(0.57-24.68)$ & 0.166 \\
\hline Primary & $33(86.8)$ & 1 & 1 & 0.859 \\
\hline Secondary and vocational & 70 (90.9) & $1.51(0.45-5.13)$ & $0.87(0.18-4.22)$ & 0.105 \\
\hline Higher & $46(93.9)$ & $2.32(0.52-10.41)$ & $7.00(0.67-73.74)$ & \\
\hline Number of live children & $2.45(1.8)$ & $1.16(0.87-1.55)$ & $1.55(0.85-2.85)$ & 0.155 \\
\hline \multicolumn{5}{|l|}{ FP method adopted } \\
\hline Injectable & $166(95.4)$ & $4.86(1.85-12.77)$ & $4.54(1.22-16.83)$ & 0.024 \\
\hline Non injectable & $47(81.0)$ & 1 & 1 & \\
\hline Duration of FP use (months) & $6.9(10.6)$ & $1.04(0.97-1.11)$ & $1.08(0.99-1.19)$ & 0.093 \\
\hline
\end{tabular}

Hosmer-Lemeshow test for goodness-of-fit: chi2 (8 d.f.) $=7.64 ; p=0.470$

Woman's occupation and Partner's occupation were not included in bivariate and multivariate analyses because of correlation with respectively woman and partner's level of education

$O R$ odds ratios, $\mathrm{Cl}$ confidence interval, IUD intra uterine device

a Multivariate analysis adjusting for possible confounding factors

Previous reports have emphasized the fact that violence against women is still considered in many settings as normal including by women themselves [19, 28]. For instance the Guinean 2012 Demographic and Health Survey (DHS 2012) [29] reported that more than half of women in the country believe a man is justified in beating his wife if she argues with him (77.6\%), goes out without his permission $(82.7 \%)$, or refuses sexual intercourse (69.7\%). In the DHS 2012, only $28 \%$ of women said a woman is justified in refusing sexual intercourse with her husband no matter what her reason is. In such a context, using a discreet and concealable method-such as injectable-that 
is fully controlled by the woman enables her to safeguard her sexual and reproductive health, and achieve her contraceptive goals. Contraceptive methods other than the injectable, such as pills and implants, are more visible, more difficult to conceal, or easily detected by the male partner. They were therefore less preferred by victims of IPV as their discovery could lead to the resumption of and/or an increase in violence $[18,28]$. Despite being a discrete method, IUD use was not associated with higher risk of IPV probably because it is not widely used in the country as is injectable [29].

Our study has some limitations. The sample size was small and the study period was short, which limit generalization of the findings to all family planning clients in Guinea. Furthermore, this was a cross-sectional study that does not allow exploring causality or verifying the answers provided by respondents. Finally, we did not screen for recent (i.e. previous 12 months) experience of IPV, and instead captured violence at any point in their relationship, which could have inflated reports of IPV compared to other study instruments, especially considering that almost $70 \%$ of women in our sample were aged 25 years and more. Despite these limitations, our findings provide evidence of the high prevalence of IPV among FP clients in Guinea.

\section{Conclusion}

IPV is prevalent among family planning clients in Conakry, Guinea where nine out of ten women screened in the AGBEF adult clinic reported having experienced one or another type of IPV. This is among the highest findings reported to date. The overlapping of the three types of violence accounted for $24 \%$ and was the most common reported feature of IPV. More efforts are needed to address this situation through a holistic approach that includes promotion of women's rights and gender equality, sexual and gender based violence (SGBV) prevention programming, existence of laws and policies to prevent and respond to SGBV, effective implementation of policies and laws, and access to quality SGBV services (including legal, psychosocial, and health) in Guinea and countries with higher rates of IPV [30,31].

Further work is needed to understand the process of IPV and evaluate the impact of interventions aimed at screening and or managing IPV in public and private health settings.

\footnotetext{
Abbreviations

AGBEF: Association Guinéenne pour le Bien-Etre Familial (Guinean Family Wellbeing Association); AOR: adjusted odds ratio; Cl: confidence intervals; IPV: intimate partner violence; IPPF: International Planned Parenthood Federation; IUD: intra uterine device; OR: odds ratio; FP: family planning; SGBV: sexual and gender based violence; STI: sexually transmitted infections; WHO: World Health Organisation.
}

\section{Authors' contributions}

$F V$, KL, DW conceived and designed the experiments. AD, GS, FV, KL, DW conceived the study design. AD, PT, FGD, MS, MT implemented the pilot project. $A D, G S, F G D$ conducted the evaluation. AD, BSC, GS collected and analysed the data and drafted the manuscript. All authors read and approved the final manuscript.

\section{Author details}

${ }^{1}$ Centre National de formation et de recherche en santé rurale de Maferinyah, Forécariah, Guinea. ${ }^{2}$ Department of Public Health, Faculty of Medicine, University of Conakry, Conakry, Guinea. ${ }^{3}$ EngenderHealth, New York, USA.

${ }^{4}$ Association Guinéenne pour le Bien-Etre Familial, Conakry, Guinea. ${ }^{5}$ Ministry of Health, Conakry, Guinea. ${ }^{6}$ EngenderHealth, Conakry, Guinea.

\section{Acknowledgements}

We are grateful to the U.S. Agency for International Development (USAID) for funding the IPV/FP pilot project under the terms of cooperative agreement GPO-A-000-08-00007-00. Our thanks also go to the study participants for their participation in the study.

\section{Competing interests}

The authors declare that they have no competing interests.

Received: 9 January 2015 Accepted: 16 December 2015 Published online: 23 December 2015

\section{References}

1. Sarkar NN. The impact of intimate partner violence on women's reproductive health and pregnancy outcome. J Obstet Gynaecol. 2008;28:266-71.

2. Campbell JC. The health consequences of intimate partner violence. Lancet. 2012;359:1131-336.

3. Garcia-Moreno C, Jansen HA, Ellsberg M, Heise L, Watts $\mathrm{CH}$. Prevalence of intimate partner violence: findings from the WHO multi-country study on women's health and domestic violence. Lancet. 2006;368:1260-9.

4. WHO, LSHTM, SAMRC. Global and regional estimates of violence against women: prevalence and health effects of intimate partner violence and non-partner sexual violence. Edited by World Health Organization. 2013. Geneva, WHO.

5. Stockl H, Devries K, Rotstein A, Abrahams N, Campbell J, Watts C, et al. The global prevalence of intimate partner homicide: a systematic review. Lancet. 2013;382:859-65.

6. Rahman M, Nakamura K, Seino K, Kizuki M. Intimate partner violence and use of reproductive health services among married women: evidence from a national Bangladeshi sample. BMC Public Health. 2012;12:913.

7. Meekers D, Pallin SC, Hutchinson P. Prevalence and correlates of physical, psychological, and sexual intimate partner violence in Bolivia. Glob Public Health. 2013;8:588-606.

8. Abeya SG, Afework MF, Yalew AW. Intimate partner violence against women in western Ethiopia: prevalence, patterns, and associated factors. BMC Public Health. 2011;11:913.

9. Bazargan-Hejazi S, Medeiros S, Mohammadi R, Lin J, Dalal K. Patterns of intimate partner violence: a study of female victims in Malawi. J Inj Violence Res. 2013;5:38-50.

10. Al-Atrushi HH, Al-Tawil NG, Shabila NP, Al-Hadithi TS. Intimate partner violence against women in the Erbil city of the Kurdistan region, Iraq. BMC Womens Health. 2013;13:37.

11. Osinde MO, Kaye DK, Kakaire O. Intimate partner violence among women with HIV infection in rural Uganda: critical implications for policy and practice. BMC Womens Health. 2011;11:50.

12. Karamagi CA, Tumwine JK, Tylleskar T, Heggenhougen K. Intimate partner violence against women in eastern Uganda: implications for HIV prevention. BMC Public Health. 2006;6:284.

13. Shamu S, Abrahams N, Zarowsky C, Shefer T, Temmerman M. Intimate partner violence during pregnancy in Zimbabwe: a cross-sectional study of prevalence, predictors and associations with HIV. Trop Med Int Health. 2013;18:696-711. 
14. Ntaganira J, Muula AS, Siziya S, Stoskopf C, Rudatsikira E. Factors associated with intimate partner violence among pregnant rural women in Rwanda. Rural Remote Health. 2009;9:1153.

15. Coker AL, Richter DL. Violence against women in Sierra Leone: frequency and correlates of intimate partner violence and forced sexual intercourse. Afr J Reprod Health. 1998;2(1):61-72.

16. Ellsberg M, Jansen HA, Heise L, Watts CH, Garcia-Moreno C. WHO, Multi-country Study on Women's Health and Domestic Violence against Women Study Team. Intimate partner violence and women's physical and mental health in the WHO multi-country study on women's health and domestic violence: an observational study. Lancet. 2008;371(9619):116572. doi:10.1016/S0140-6736(08)60522-X.

17. Alio AP, Daley EM, Nana PN, Duan J, Salihu HM. Intimate partner violence and contraception use among women in Sub-Saharan Africa. Int J Gynaecol Obstet. 2009;107:35-8.

18. O'Hara K, Tsai LC, Carlson CE, Haidar YM. Experiences of intimate-partner violence and contraception use among ever-married women in Jordan. East Mediterr Health J. 2013;19:876-82.

19. Institut National des Statistiques G. Enquete Demographique et de sante-Etude a indicateurs multiples (EDS-MICS), Guinee 2012. 2014. Conakry, INS; Macro Int.

20. Delamou A, Koivogui A, Dubourg D, Delvaux T. Family planning in Guinea: a need for better public commitment. Trop Med Int Health. 2014;19:65-73.

21. Delamou A, Samandari G. Integrating intimate partner violence screening and counseling with family planning services: Experience in Conakry, Guinea. Edited by The RESPOND Project Study Series: Contributions to Global Knowledge-Report No.16. 2014. New York, EngenderHealth (The RESPOND Project).

22. Rinehart W, Rudy S, Drennan M: GATHER guide to counseling. Popul Rep J $1998 ; 1-31$
23. Basile KC, Hertz MF, Back SE. Intimate Partner Violence and Sexual Violence Victimization Assessment Instruments for Use in Healthcare Settings: Version 1. Atlanta (GA): Centers for Disease Control and Prevention, National Center for Injury Prevention and Control; 2007.

24. Bott S, Guedes A, Claramunt MC, Guezmes A. Improving the health sector response to gender based violence a resource manual for health care professionals in developing countries. New York: International Planned Parenthood Federation, Western Hemisphere Region; 2010.

25. Ministere des Affaires Sociales G. Enquête nationale sur la violence á l'égard des femmes et des hommes. Edited by MASPFE. 2009. Conakry, Ministere des Affaires Sociales, UNFPA, UNICEF.

26. Laisser RM, Nystrom L, Lindmark G, Lugina HI, Emmelin M. Screening of women for intimate partner violence: a pilot intervention at an outpatient department in Tanzania. Glob Health Action. 2011;4:7288.

27. Dalal K, Andrews J, Dawad S. Contraception use and associations with intimate partner violence among women in Bangladesh. J Biosoc Sci. 2012:44:83-94.

28. Deribe K, Beyene B, Tolla A, Memiah P, Biadgilign S, Amberbir A. Magnitude and Correlates of Intimate Partner Violence against Women and Its Outcome in Southwest Ethiopia. PLoS One. 2012;7:e36189. doi:10.1371/ journal.pone.0036189.

29. Institut National des Statistiques G. In: Mesures DHS, editor. Enquête Démographique et de Santé et a Indicateurs Multiples, Guinée 2012. 2014. Claverton, Maryland, USA, INS \& Macro.

30. Ellsberg M, Arango D, Morton M. Prevention of violence against women and girls: what does the evidence say? Lancet. 2014. doi:10.1016/ s0140-6736(14)61703-7.

31. Garcia-Moreno C, Zimmerman C, Morris-Gehring A, Heise L, Amin A Abrahams N, et al. Addressing violence against women: a call to action. Lancet. 2014. doi:10.1016/S0140-6736(14)61830-4.

\section{Submit your next manuscript to BioMed Central and we will help you at every step:}

- We accept pre-submission inquiries

- Our selector tool helps you to find the most relevant journal

- We provide round the clock customer support

- Convenient online submission

- Thorough peer review

- Inclusion in PubMed and all major indexing services

- Maximum visibility for your research

Submit your manuscript at www.biomedcentral.com/submit 